\title{
RETRACTION: Dietary Intake of Omega-3 Fatty Acids and Endocrine-Related Gynecological Cancer: A Meta-Analysis of Observational Studies
}

The Editors and the Publisher have retracted this article [1] because of serious similarity with the previously published article [2]. Following an information raised by one of our readers, the Editors and Publisher confirmed that some of the sentences are similar in writing, style, and ordering of the references. SKM, the corresponding author, did not agree on this retraction. TH, the first author, and TTP, the co-author could not be reached.

\section{References}

1. Hoang T, Myung SK, Pham TT. Dietary intake of omega-3 fatty acids and endocrine-related gynecological cancer: a meta-analysis of observational studies. Cancer Res Treat. 2019;51:1022-32.

2. Brasky TM, Rodabough RJ, Liu J, Kurta ML, Wise LA, Orchard TS, et al. Long-chain $\omega$-3 fatty acid intake and endometrial cancer risk in the Women's Health Initiative. Am J Clin Nutr. 2015;101:824-34. 